\title{
CIÊNCIANATURA
}

\section{Eigendecomposition filtering and reconstruction climatic indexes for the Brazilian Northeast}

\author{
Cleber Souza Corrêa ${ }^{1}$, Roberto Lage Guedes ${ }^{1}$ and Karlmer Abel Bueno Corrêa ${ }^{2}$
}

\author{
${ }^{1}$ Instituto de Aeronáutica e Espaço (IAE), São Jose dos Campos, Brazil \\ clebercsc@fab.mil.br and roblg331@gmail.com \\ ${ }^{2}$ Escola Superior de Agricultura "Luiz de Queiroz" - ESALQ/USP, Brazil \\ karlmerabc@usp.br
}

\begin{abstract}
This work seeks through the intermediary of the eigendecomposition filtering and reconstructing technique the signal time series of Southern Oscillation Index (SOI) and analyze possible cycles that can be observed in this SOI time series. The technique of decomposition was very consistent and can show possible trends in cycles in time series of SOI. The final result is featuring a composition of components that operate in the formation of SOI signal variability, the first component is featuring approximately 1.33, 2.66, 3.58, 4.83 years and decadal time period, larger scales and periods, matching a variance approximately of $70 \%$ of the signal of the SOI time series. In addition to the influence of solar activity cycles, associated with its sunspots number, the variability observed from 20 to 27 years may be related to the interaction between Pacific Decadal Oscillation (PDO) and Southern Oscillation Index (SOI). The understanding of the dynamics that control the decadal variability in the Pacific Ocean and its interactions with climate change on a global scale. These results can be correlated to the atmospheric dynamics behavior characteristics and predominance in northeastern Brazil, and it has importance affecting activities in Rocket Launch Centre in Alcântara.
\end{abstract}

Keywords: Time-series analysis, Eigendecomposition filtering and Reconstruction, Southern Oscillation Index. 


\section{Introduction}

In the literature there are studies that evaluate the Southern Oscillation Index (SOI) variability, which has a biannual signal variation component, Ropelewski and Jones (1987), Elliott and Angell (1988), Rao and Hada (1990), Grimm, et al. (1998), Kayano and Andreoli (2006), Capotondi et al. (2015), and Astudillo et al. (2016), Rasmuson et al. (1990), using surface marine wind and sea surface temperature data from the period 1950-1987, together with sea surface temperature and sea level pressure data from several stations in the Pacific, it was identified two dominant time scales of El Niño-Southern Oscillation (ENSO) variability. One is a biennial mode, with periods near 24 months, the other a lower frequency concentration of variance in periods of four to five years. A particularly well defined standing biennial component of ENSO variability, tightly phase-locked with the annual cycle, appears in the surface wind field of the equatorial eastern Indian Ocean. This is part of a larger scale biennial circulation over the low latitude eastern Indian Ocean-western Pacific sector. This biennial circulation is a fundamental ENSO variability element. It exhibits a strong tendency for phase locking with the annual cycle and introduces a degree of regularity into the ENSO cycle. Astudillo et al. (2016) show that the information contained in the SOI is sufficient to provide nonlinear attractor information, allowing the detection of predictability for longer than a year: 2,3 , and 4 years in advance throughout the record with an acceptable error. This is possible due to the fact that the lower-frequency variability of the SOI presents long-term positive autocorrelation.

There are works that make reference to the variability of SOI/ENSO with the Pacific Decadal Oscillation (PDO) variability, Newman et al. (2003). Rodgers et al. (2004), Zhang and Church (2012), Gu and Adler (2013) and Kucharski et al. (2015), aimed at understanding the dynamics that control the decadal variability in the Pacific Ocean and its interactions with climate change on a global scale.

Stauning (2011), shows that the solar activity-climate relations is extended with the most recent sunspot and global temperature data series. There is a strong correlation between solar activity and terrestrial temperatures delayed by 3 years. A regression analysis between solar activity represented by the cycle-average sunspot number, and global temperature anomalies, averaged over the same interval lengths, but delayed by 3 years. It is suggested that the in-cycle variations and also the longer-term variations in global temperatures over the examined 135 years are mainly caused by corresponding changes in the total solar irradiance level representing the energy output from the solar core, but further modulated by varying energy transmission properties in the active outer Sun regions.

The relationship between the solar energy net balance that reaches the surface of the earth and especially in the oceans directly affects the climatic cycles in the earth system ocean-atmosphere, there are some works that relate that for the climatological annual cycle and for interannual-to-decadal scales suggested that the solar-related signals in the upper ocean temperature can penetrate to $80-160 \mathrm{~m}$ depth, and its influence on behavior in climatic time series and the decadal scales, Ellias et al. (1978), Levitus et al. (2000), Willis et al. (2004) and Levitus et al. (2012).

Lassen and Friis-Christensen (1995) showed that the solar cycle length duration in the last past five centuries been associated with the Earth's climate, with a well-defined activity with a cycle of eleven years in the number of sunspots. Since solar activity approximately 11-year cycles ranged from 8-17 years within a period of 80-90 years.

This behavior of cycles analysis is important because with the increase of series SOI, allow it to be calculated by eigendecomposition components which separate the long-range variation over time of the high frequency part of SOI series. Allowing a more detailed analysis is made of the behavior time scales of SOI/ENSO variability.

The identification, isolation, and reconstruction of signal components via eigendecomposition is known by a variety of names. Singular Spectrum Analysis, Principal Component Analysis, and Eigenfiltering are common. This research work exclusively uses the Eigendecomposition filtering and Reconstruction designation since it represents a more precise description of the numeric method, Ghil et al. (2002), Elsner and Tsonis (2013). Recognition of possible cycles in the SOI/ENSO time series allow occurs better behavior patterns recognition, which can help in a better use of this information in the safety and planning activities of the Rocket Alcântara Launching Center (ALC).

\section{Methodology}

\subsection{Eigendecomposition filtering and reconstruction}

An excellent reference to show the equations model used by eigendecomposition in the work was done by Elsner and Tsonis (2013). Also, a public domain FORTRAN Eigenanalysis toolkit, known as the Singular Spectrum Analysis Toolkit is available at http://www.atmos.ucla.edu/tcd/ssa.

The Autosignal (C) software 1.6 for windows using the eigendecomposition algorithms vary only by how a lagged covariance matrix is constructed: using the covariance matrix equivalent of processing a forward-backward prediction data matrix (CovM FB). The decomposition of a forward-backward data matrix produces the eigenvalues and eigenvectors as the equivalent co- 
variance matrix and requires more processing time with large data sets.

In this procedure, the main task is to isolate and reconstruct signal components of interest by selecting one or more eigenmodes. The noise is broken into low power elements that generally form a sloping floor beyond the signal eigenmodes in the eigenvalue plot. Establishing the eigendecomposition order for harmonic signals in the absence of noise is a simple matter. A model order of two is needed to fully describe one oscillation. Similarly, an order of four is needed to fully model two oscillatory components. For noise-free data, the minimum order needed will be twice the number of signal components introducing oscillations in the data. These oscillatory components can be harmonic, such as undamped or damped sinusoids, sawtooth, and others. Or they can be anharmonic, oscillations where the model is not readily apparent.

Since there is usually some level of noise present in the data, a higher order model is needed to also account for the oscillations introduced by noise. To achieve a reasonable signal-noise separation within an eigendecomposition, it is necessary to use a high enough order so that the primary eigenvectors span only signal space. Further, when isolating components, the partitioning of component signals into different eigenmodes is usually enhanced by higher orders. The Normalize (\%) item plots the eigenvalues on a percent scale. When this normalization is used, all of the eigenvalues sum to $100 \%$, characterizing total variance of the studied SOI time series. This option makes it easy to see the relative contribution, by eigenvalue, of each component.

The Eigenvectors option was selected, each of the eigenvectors used in the reconstruction is plotted. Each eigenvector plotted will be of the length of the embedding dimension (model order). Sinusoidal harmonics will generally appear in pairs, one offset in index from the other.

\subsection{Autocorrelation function}

For each component calculated on the eigendecomposition it was calculated autocorrelation function and it was computed using the Prime factor FFT algorithm following Temperton (1985). The graph generated is normalized using $1 / \mathrm{N}$ for data length. This procedure allows filtering the high frequencies in the SOI signal analysis and the first component shows the variability filtered without high frequency ranges allowing a more correct analysis. It was performed the calculation of the time series data autocorrelation function of the Monthly mean the total sunspot number.

\subsection{Time series data}

\subsubsection{Southern oscillation index (soi)}

The SOI data were obtained from the National Weather Service - Climate Prediction Center (www.cpc.ncep.noaa.gov/data/indices/) web page. For the SOI data monthly information and normalized in the 1951-2015 period were used, in total there were 775 months with SOI value, about 65 years in the analyzed time series.

\subsection{Pacific decadal oscillation (pdo)}

Pacific Decadal Oscillation Index was derived as the leading Principal Component of monthly SST anomalies in the North Pacific Ocean, poleward of 20N. The monthly mean global average SST anomalies are removed to separate this pattern of variability from any "global warming" signal that may be present in the data. Zhang et al. (1997) and Mantua et al. (1997). PDO index data were obtained from the NOAA website (http://www.ncdc.noaa.gov/teleconnections/pdo/), it was download as a data.csv file with the index information, about 162 years in the analyzed time series, with monthly values.

\subsection{Monthly mean total sunspot number}

The monthly mean total Sunspot number data were obtained from the http://www.sidc.be/silso/datafiles site (Sunspot data from the World Data Center SILSO, Royal Observatory of Belgium, Brussels), from where it was download the data file (SN_m_tot_V2. txt) with the information of the sunspots activities, from 1749 to 2016 with a 267 years series.

\section{Results}

\subsection{Eigendecomposition}

The results obtained using the eigendecomposition technique filtering and reconstruction, showed very interesting results. To allowed the SOI signal could be separated into components, which allow separate high frequency component signal. Allowing to define the cycles with greater temporal scale. Figure 1 graphically represents the function of three components (eigenmodes), showing the different signals that compose the SOI variability time series. 
Figure 1 - shows the result of eigendecomposition with three components

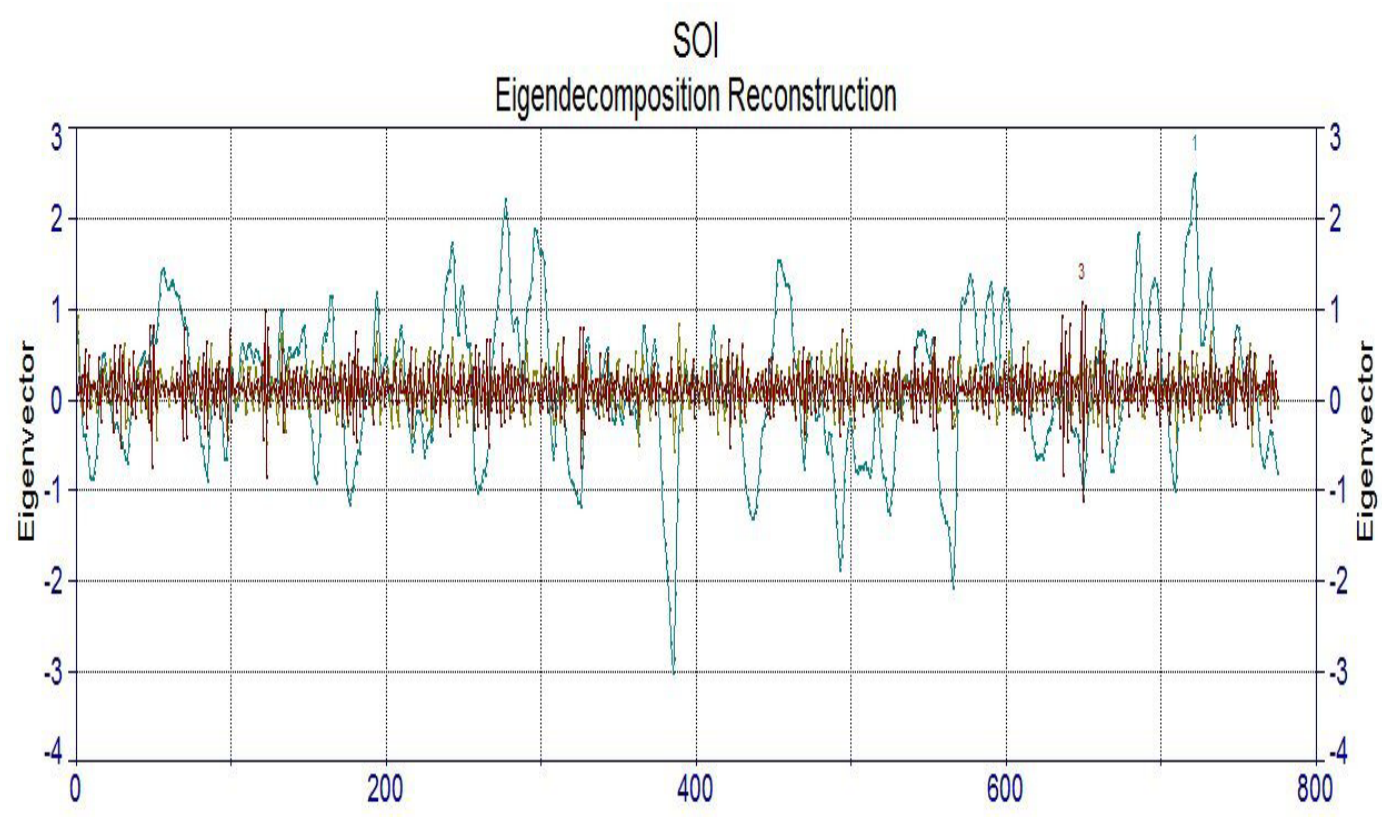

In figure 2 shows the three components that are built to form the SOI signal variation, this technique was applied to the complete time series, showing the reconstruction of the original SOI time series. Figure 3 shows that the first component has the highest variance explained and it can be related to frequency order from one to two years, responsible component to represent a period of decadal scale in the time series. The second component can be associated with a frequency order from 2 to 4-month, intra-seasonal timescale, and the third or largest component is associated with noise process.

Figure 2 - the SOI time series built by the eigendecomposition filtering with three components

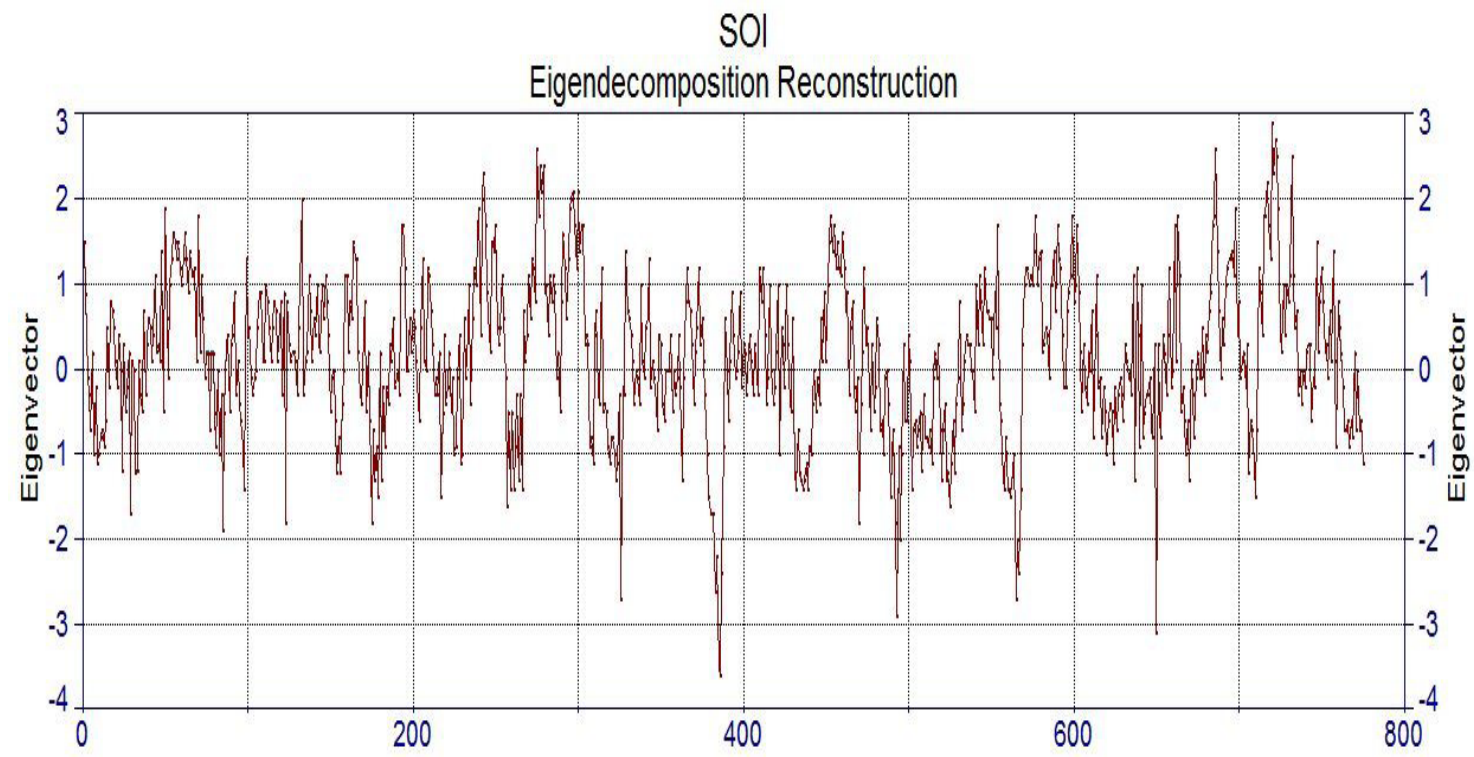


Figure 3 - shows the result with eigenvalue normalized of eigendecomposition filtering with three components

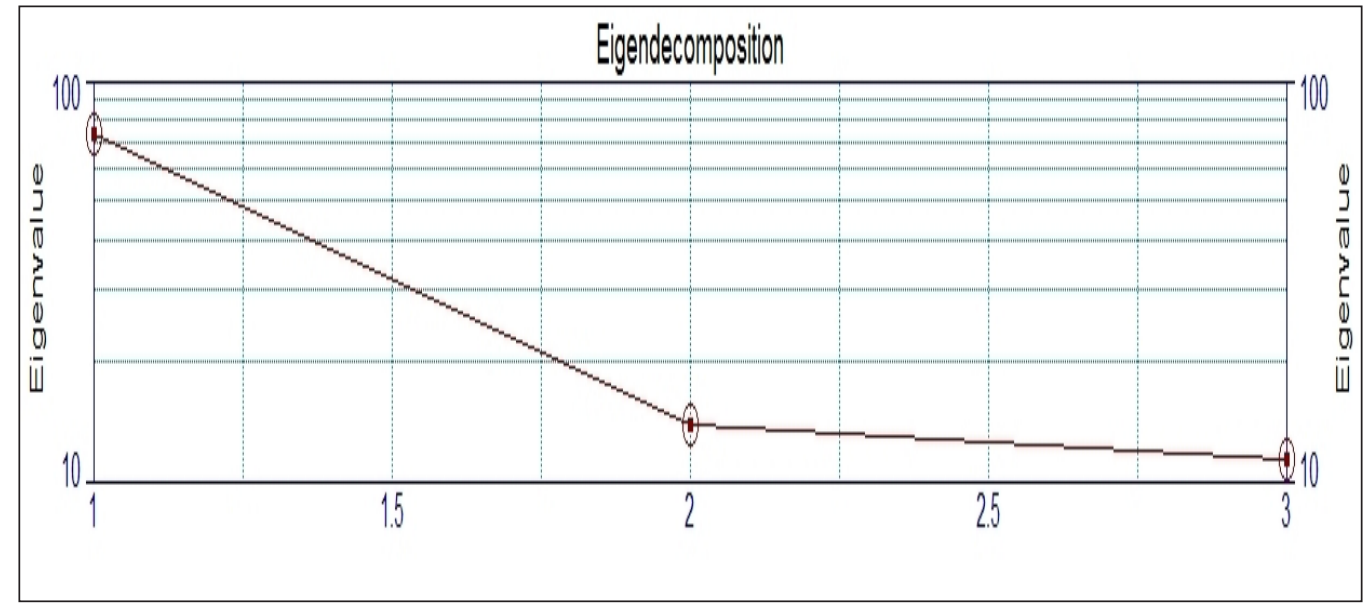

In figure 4 shows the eigenvector per component, which can be associated with the third or largest components have a wave like sinusoidal variation in the SOI series signal behavior.

Figure 4 - shows the three components of eigenvector obtained in the eigendecomposition

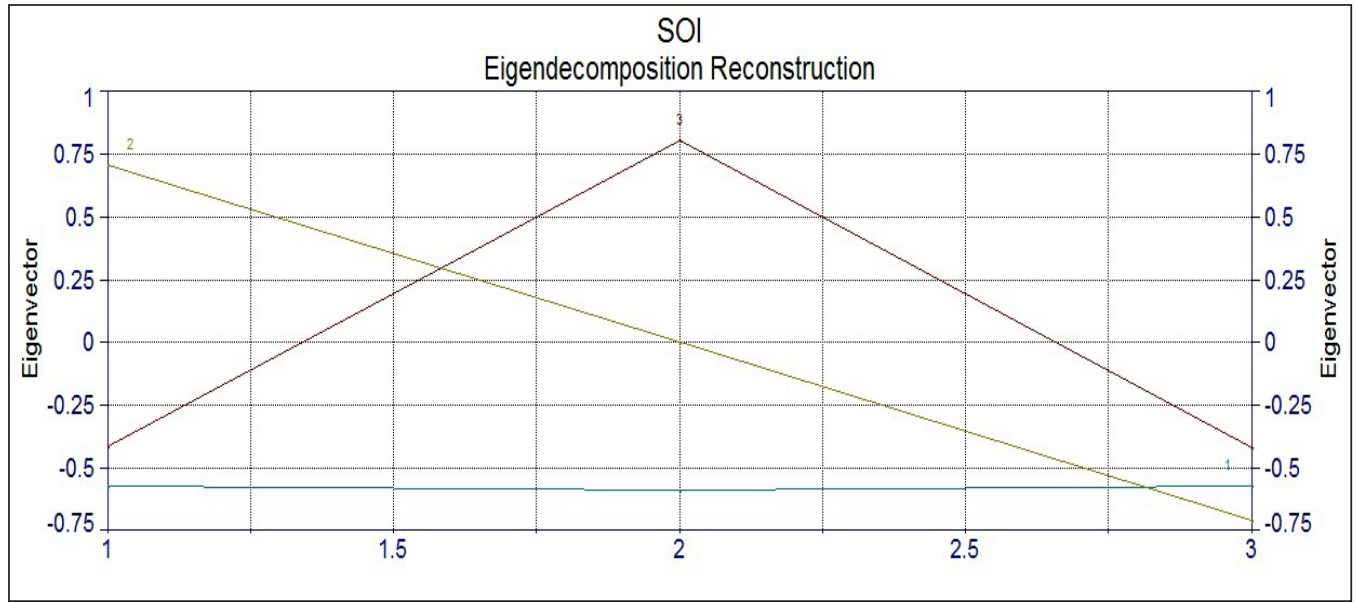

In Figures 5, 6, 7 and 8 it is shown the eigendecomposition with greater number of components in the SOI series. Figure 5 and 6 with four components and Figure 7 and 8 with five components.

Figure 5 - shows the result with eigenvalue normalized of eigendecomposition filtering with four components

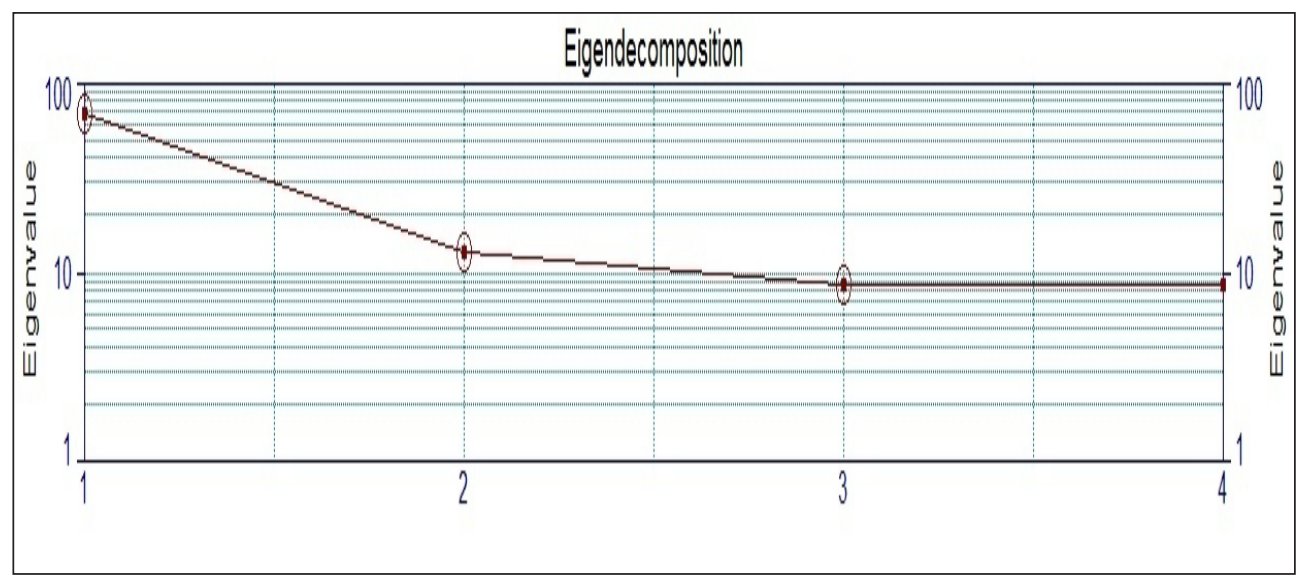


Figure 6 - shows the four components of eigenvector obtained in the eigendecomposition

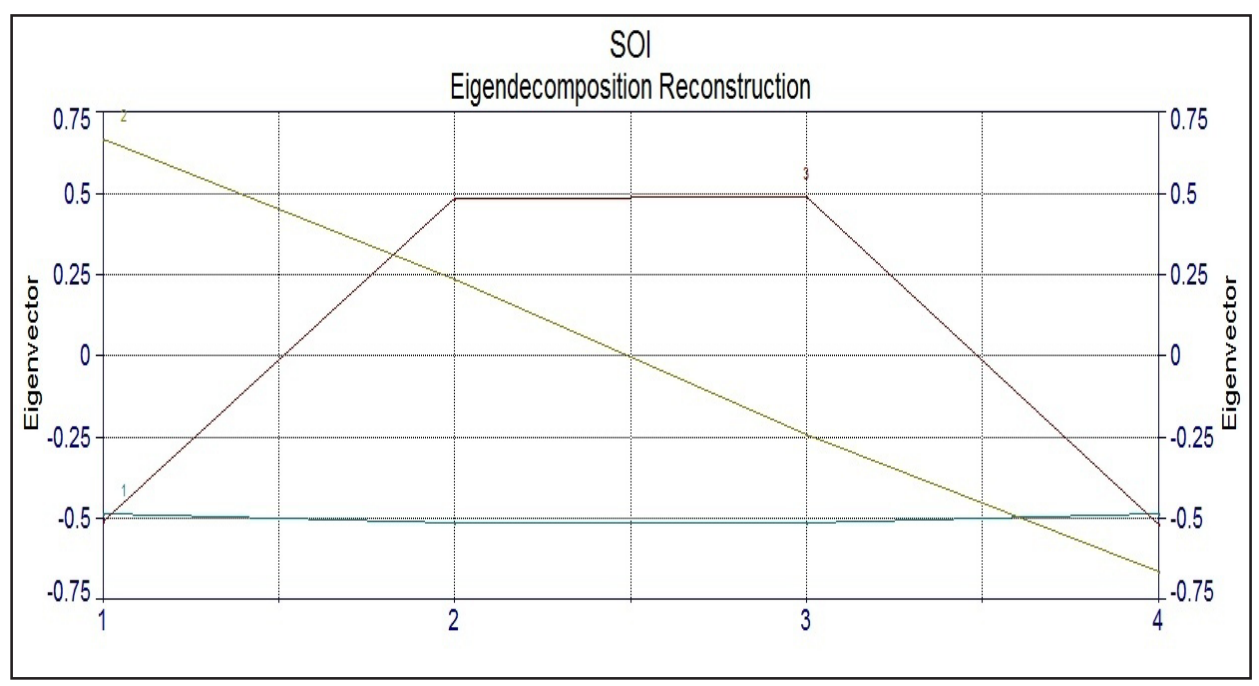

Figure 7 - shows the result with eigenvalue normalized of eigendecomposition filtering of five components

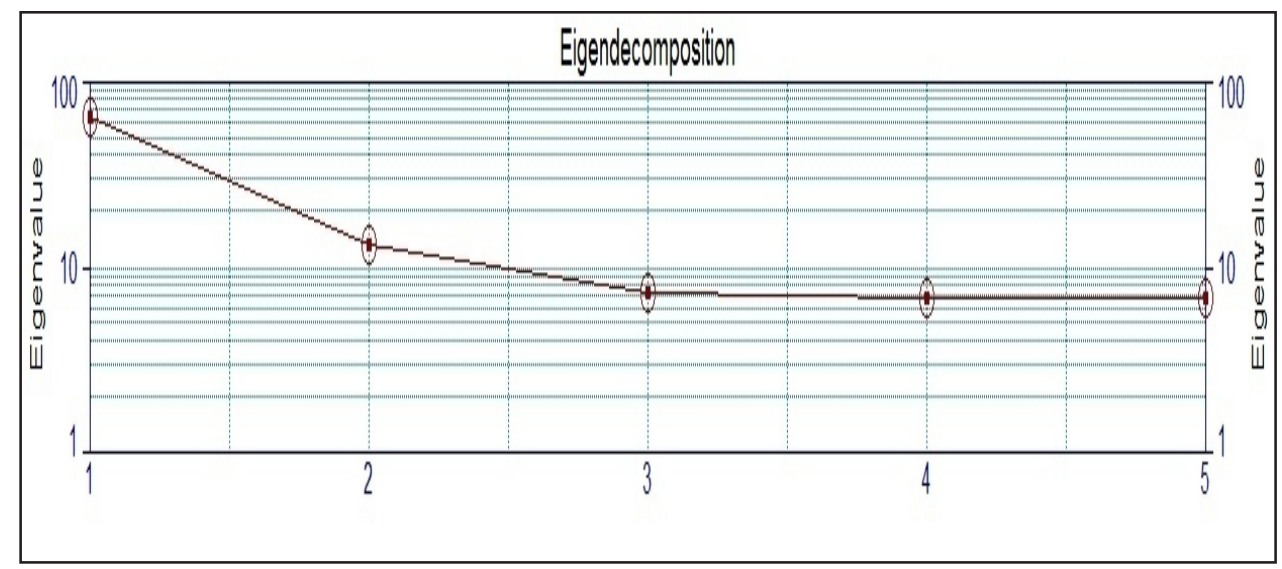

In Figure 8 with 5 components, it is shown that the third, fourth and fifth components have a sinusoidal behavior in the SOI series signal and are lagged in time, these components may be associated with high-frequency characteristics, with noise process associated scales, creating high complexity in time series.

Figure 8 - shows the five components of eigenvector obtained in the eigendecomposition

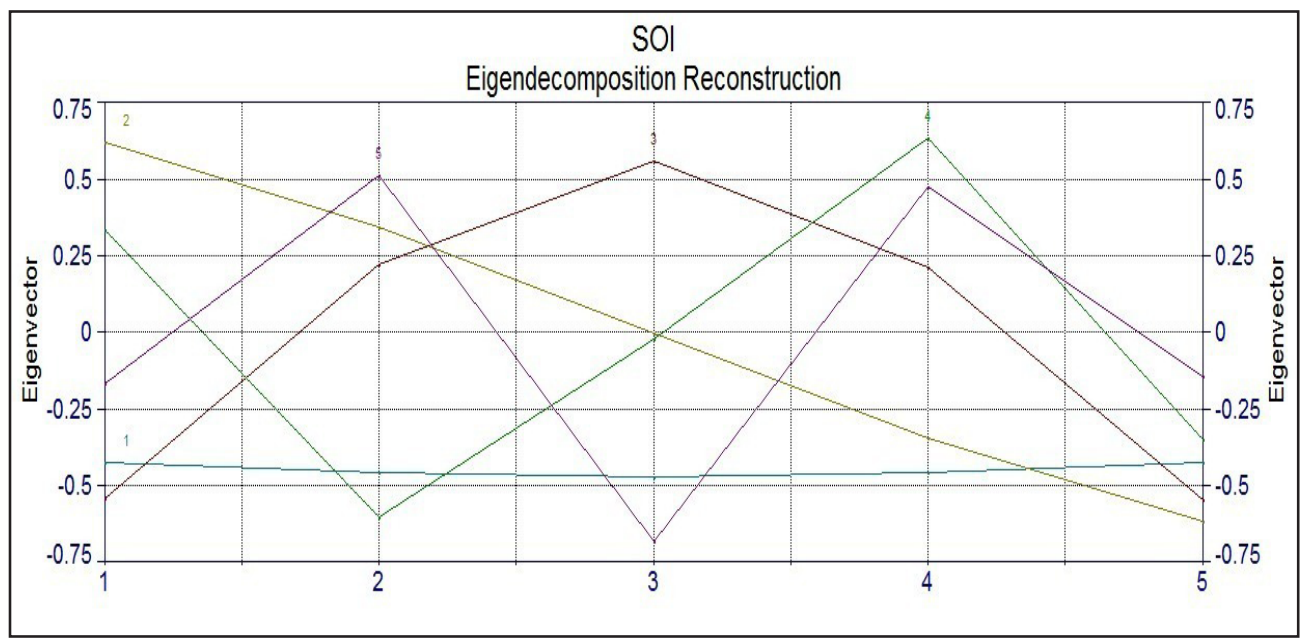


This behavior implies a very large complexity in SOI series time, because these eigenmodes characterize the high frequency variability ranges behavior, and these scales are propagated in SOI signal. The order of one, two and three years with influences of these eigenmodes of greater order with high frequency scale, are lagged in time. This result is consistent with Astudillo et al. (2016) work, which showed it allows the detection of predictability for longer than a year: 2,3 , and 4 years in advance. Because the components show characteristics persistence are propagated in the analyzed time series.

Table I shows the eigenvalues values, which represent the SOI time series variance explained behavior variability. This result shows that the eigendecomposition of three, four and five components (eigenmodes) total variance explained very significantly the SOI time series behavior, whose values explain nearly all the variance.

Table I - The Eigenvalues resulting with Eigendecomposition for 3, 4, 5 components

\begin{tabular}{|c|c|c|c|c|c|c|}
\hline \multicolumn{6}{|c|}{ Eigendecomposition } & \multirow[t]{2}{*}{ Total Variance (\%) } \\
\hline Eigenvalue & $1^{\mathrm{a}}$ & $2^{\mathrm{a}}$ & $3^{\mathrm{a}}$ & $4^{a}$ & $5^{\mathrm{a}}$ & \\
\hline $3^{\mathrm{a}}$ component & 74.39 & 14.07 & 11.53 & - & - & 99.99 \\
\hline $4^{\mathrm{a}}$ component & 69.54 & 13.03 & 8.8 & 8.6 & - & 99.97 \\
\hline $5^{\mathrm{a}}$ component & 65.60 & 11.6 & 7.3 & 6.9 & 6.8 & 98.2 \\
\hline
\end{tabular}

\subsection{Autocorrelation function}

Figure 9 shows some important features of cycles in the SOI time series, approximately 2.66, 4.83 years and decadal time period, approximately $10.33,12,14.91$ and 25 years with significant positive autocorrelation function and approximately $1.33,3.58,6.08,8.5,16.08$ and 26.5 years with significant negative autocorrelation function, matching a variance approximately of $70 \%$ of the SOI time series signal. The second component corresponds approximately to $13 \%$ of the total series variance, shorter timescale which may characterize a scale intra-seasonal variability with geophysical processes variability order from 2 to 4 months. The third or largest components featuring high frequency and is associated noise process, the series total variance corresponds to $8 \%$. An important feature in Figure 9 which can characterize important cycles is the autocorrelation function significant change, change positive to negative, has three significant changes in the autocorrelation function, from 3 to 6 , from 10 to 16 and 22 to 26.5 years.

Figure 9 - Autocorrelation function of the first component (SOI) (Lag is monthly timescale)

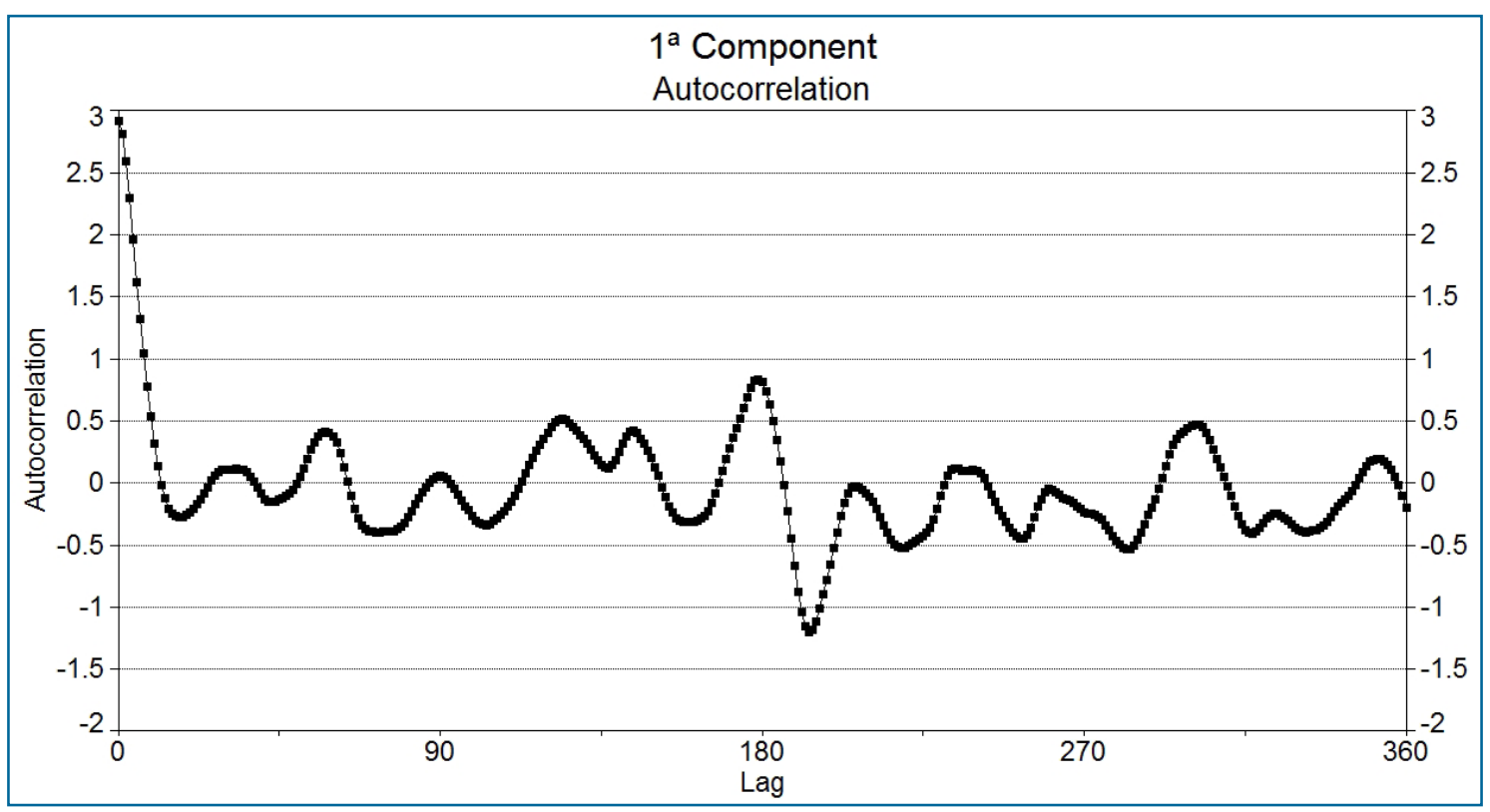


The period from 3 to 6 years can be related to the Stauning (2011) work, which noted that there is a strong correlation between solar activity and terrestrial temperatures delayed by 3 years, and they are mainly caused by corresponding changes in the total solar irradiance level representing the energy output from the core, but further modulated by varying energy transmission properties in the active outer Sun regions.

The period from 10 to 16 years can be related to the Lassen and Friis-Christensen (1995) work, which showed a well-defined activity with a cycle of eleven years in the sunspots number. Since solar activity approximately 11-year cycles ranged from 8-17 years within a period of 80-90 years. The period from 20 to 27 years can be related to the Molion (2006) work, which discusses the global mean temperature variability may be linked to the Pacific Decadal Oscillation (PDO) between a periodicity from 20 to 25 years. The figure 9 results show a significant signal autocorrelation function between this cycle and the 20 to 27 years one, and could be correlated to the PDO.

Table II shows the most significant autocorrelation function results, the highest correlations coefficients are about the periods of 14 years positively and the 16 years negatively ones. In a second magnitude degree is the 10 to 12 year positive cycle and the third period with 4.83 positive years and with 6.08 negative years. Cycles within this analyzed 65 years period showed that the SOI series shows autocorrelation function significantly in periods from 10 to 12 years and periods of 14 years, positively and negatively, with 16 and 23.58 years, and 25 positive years and finally 26.5 negative years, all coefficients with values next to or greater than 0.50 (autocorrelation function). This feature monitors the solar cycle maximum and minimum geophysical activities, which has a periodicity of 11 years, Jones et al. (1999) and Molion (2006).

In the Wang et al. (2015) work, it was shown that decadal upper ocean heat content variability in the Pacific responds to the 11-year solar cycle, and showed that there is a physical association with heat content anomaly (OHCa) time series in some areas of the Pacific are significantly correlated with the total solar irradiance (TSI). Using the composite mean-difference method, the mean response of Ocean heat content a in the upper-700m of the ocean to the TSI was determined, among the high solar response areas in two regions, one in the tropical mid-Pacific and the other in the western Pacific, where the OHCa present decadal variations, but in different phases. The phase variation of the solar response indicates that there exists an agency for the OHCa's response to TSI.

These results point to a direct influence of solar activity, with the Pacific oceanic regions temperature anomaly cycles, and consequently influence the changes and SOI modulations, which can be seen in figure 9, which shows the obtained autocorrelation function.

TABLE II - Results analysis with first component autocorrelation (SOI)

\begin{tabular}{c|c}
\hline \multicolumn{2}{c}{ Autocorrelation (Years) } \\
\hline Negative & Positive \\
\hline 1.33 & 2.66 \\
\hline- & - \\
\hline 3.58 & 4.83 \\
\hline- & - \\
\hline $6-8.50$ range & $10-12$ range \\
\hline- & - \\
\hline 13.33 & 14.91 \\
\hline- & - \\
\hline 16.08 & - \\
\hline 23.58 & 25.16 \\
\hline- & - \\
\hline 26.5 & \\
\hline
\end{tabular}


Table II presents a very significant feature, which shows a range between positive and negative correlations between a cycle from 8 to 16 years, consistent with the Lassen and Friis-Christensen (1995) work, which showed that sunspot activity and the consequent variation change has been found to be strongly correlated with long-term variations in the global temperature, significantly affecting the climatic dynamics on Earth (example SOI time series).

Figure 10 and Table III show the autocorrelation function of the monthly mean Sunspots number, show much resemblance to the autocorrelation function of the SOI -Monthly mean total Sunspot number series, showing similarity between the calculated spectrum in periods 4.83 to 5,10 to 10,16 to $16,21.41$ to $23,58,24.66-26.5$ to 26.91 years.

Figure 10 - Autocorrelation function with Monthly mean total sunspot number (Lag is monthly timescale)

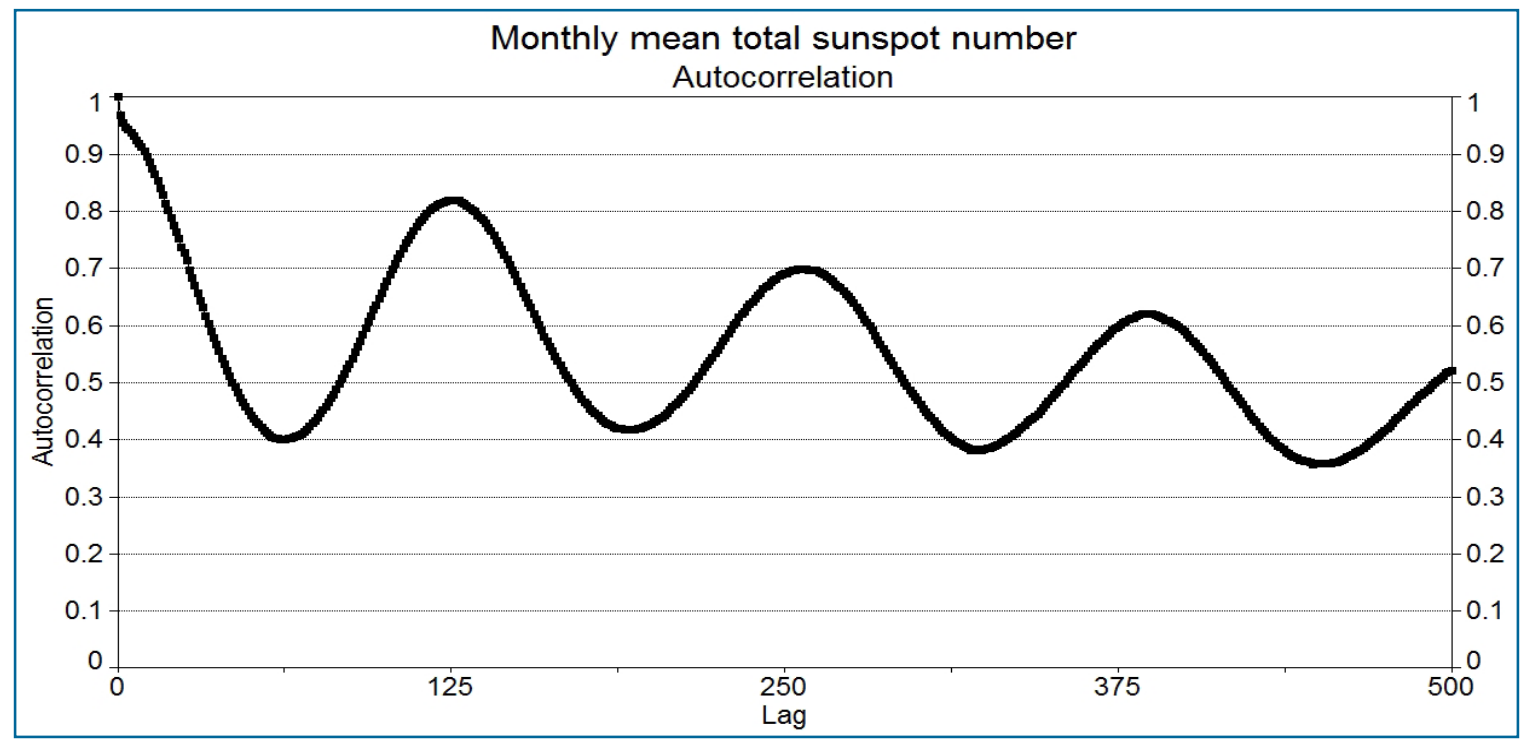

Table III - Results analysis with autocorrelation function of the sunspot series with monthly average values of the years 1749-2016

\begin{tabular}{l|l|l|l|l|l|l|l}
\hline \multicolumn{1}{l}{ Autocorrelation (Years) } \\
\hline Positive & 5.16 & 10.41 & 16 & 21.41 & 26.91 & 32 & 38 \\
\hline
\end{tabular}

Table IV - Results shows the comparison between the autocorrelations values of years between the SOI and the monthly average sunspot numbers time series

\begin{tabular}{c|c|c|c|c|c|c|c}
\hline \multicolumn{1}{c}{ Years } \\
\hline $\begin{array}{c}\text { Suns- } \\
\text { pot }\end{array}$ & 5.16 & 10.41 & 16.08 & 21.41 & 26.91 & 32 & 38 \\
\hline SOI & 4.83 & 10.25 & 16.16 & 23.66 & $\begin{array}{c}25.16- \\
26.5\end{array}$ & - & - \\
\hline
\end{tabular}

The results of Table IV show the similarities between the autocorrelation function and how the series of SOI its estimate only 65 years.

Figure 11 and Table V shows the PDO autocorrelation function, showing a behavior similar to that observed Sunspots and SOI time series. To periods of 4-5, 6-8.5, 10-12 and 15-17 years. However, for cycles with greater autocorrelation periods in the series, periods from 20 to 27 years or more, the behavior shows significant differences, when SOI is positive, PDO is negative and when PDO is positive, SOI is negative. Such situation can characterize the physical influence of oceanic dynamic scales, affecting the behavior of the index's and the time scale involved can characterize the partial decoupling of solar forcing on the SOI and PDO as a primary forcing dynamics, showing the internal scales interaction associated with the oceanic dynamics and consequent interaction and its atmospheric influences, affecting the global climatic dynamics, with great complexity. 
Figure 11 - Autocorrelation function of the Pacific Decadal Oscillation (Lag is monthly timescale)

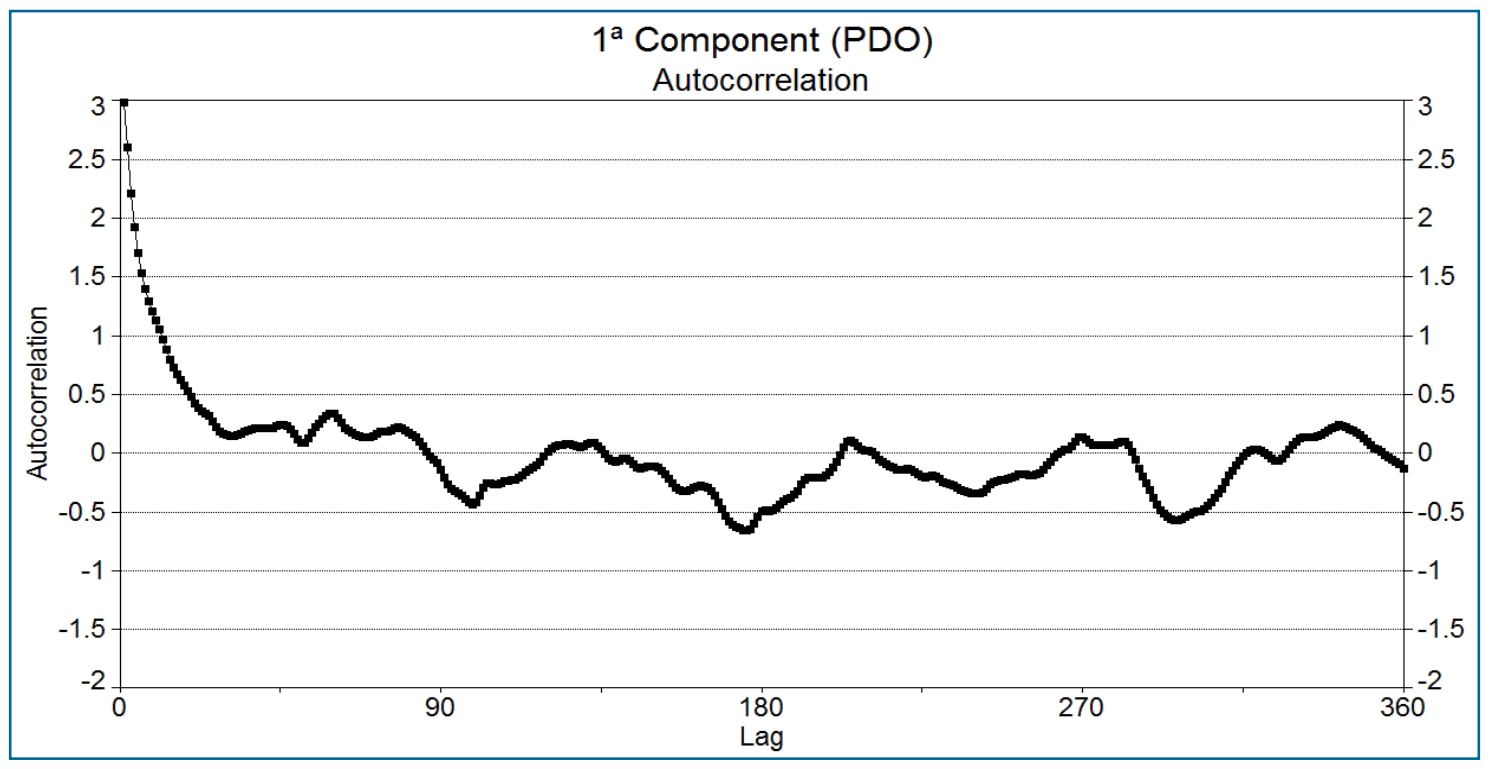

Table V - Results analysis of the first component autocorrelation (PDO)

Autocorrelation (Years)

\begin{tabular}{c|c|c|c|c|c|c|c|c|c}
\hline Negative & - & 8.25 & - & 14.58 & - & - & - & 24.66 & - \\
\hline Positive & 4.91 & - & 11 & - & 17 & 20 & 22.5 & - & 28.5 \\
\hline
\end{tabular}

\section{Discussion}

The eigendecomposition filtering technique used in the SOI time series allowed to remove the part of high frequency that would change the analysis of long-period trend. The first eigendecomposition component is responsible for about $70 \%$ of the SOI time series variation signal and $67 \%$ of PDO index variance. In the calculated autocorrelation function important cycles can be characterized when a significant change in the autocorrelation function occurs, his change positive to negative, has three significant changes in the autocorrelation function, from 3 to 6 , from 10 to 16 and 20 to 27 years, can be correlated these features in the solar activity cycles observed. In addition to the solar activity cycles influence, associated with its number of sunspots, the cycle observed from 20 to 27 years or longer period, may be related to the PDO/SOI complex interaction. An internal and complex variability between Pacific oceanic regions that define the PDO and SOI, may affect partially these indexes. These physical mechanisms have could a better understanding, it would help to understand the climatic dynamics on a global scale.

\section{Acknowledgements}

The authors thank the support of the Instituto de Aeronáutica e Espaço (IAE).

\section{References}

ASTUDILLO HF, ABARCA-DEL-RIO R, BOROTTO FA. Long-term potential nonlinear predictability of El Niño-La Niña events. Clim Dyn. (2016) doi:10.1007/s00382-016-3330-1.

CAPOTONDI A, WITTENBERG AT, NEWMAN M, LORENZO ED, YU JY, BRACONNOT P, COLE J, DEWITTE B, GIESE B, GUILYARDI E, JIN FF, KARNAUSKAS K, KIRTMAN B, LEE T, SCHNEIDER N, XUE Y, YEH SW. Understanding ENSO diversity. Bull Am Meteorol Soc. (2015) 96:921-938. doi:10.1175/BAMS-D-13-00117.1 
ELLIS JS, HAAR TH, LEVITUS S, OORT AH., The annual variation in the global heat balance of the earth. J.Geophys. Res. (1978). 83(C4),1958-1962.

ELLIOTT WP, ANGELL JK. Evidence for Changes in Southern Oscillation Relationships during the Last 100 Years. $J$. Climate, (1988) 1, 729-737, doi: 10.1175/1520-0442(1988)001<0729: EFCISO>2.0.CO;2.

ELSNER JB, TSONIS AA. Singular spectrum analysis: a new tool in time series analysis. Springer Science \& Business Media. (2013).

GHIL M, ALLEN MR, DETTINGER MD, IDE K, KONDRASHOV D, MANN ME, YIOU P. Advanced spectral methods for climatic time series. Reviews of geophysics, (2002). 40(1). doi: 10.1029/2000RG000092

GRIMM AM, FERRAZ SE, GOMES J. Precipitation anomalies in southern Brazil associated with El Niño and La Niña events. Journal of climate, (1998). 11(11), 2863-2880.

GU G, ADLER RF. Interdecadal variability/long-term changes in global precipitation patterns during the past three decades: global warming and/or pacific decadal variability?. Climate dynamics, (2013). 40(11-12), 3009-3022. doi: 10.1007/ s00382-012-1443-8

JONES PD, NEW M, PARKER DE, MARTIN S, RIGOR IG. Surface air temperature and its changes over the past 150 years. Rev. Geophys. (1999). 37, 173-199.

KAYANO MT, ANDREOLI RV. Relationships between rainfall anomalies over northeastern Brazil and the El Nino-Southern Oscillation. Journal of Geophysical Research: Atmospheres, (2006). 111 (D13).

KUCHARSKI F, IKRAM F, MOLTENI F, FARNETI R, NO HH, KING MP, KANG IS. Atlantic forcing of Pacific decadal variability: Forcing of long-term trend and Pacific Climate Shifts. In EGU General Assembly Conference Abstracts (2015). (Vol. 17, p. 11627).

LASSEN K, FRIIS-CHRISTENSEN E. Variability of the solar cycle length during the past five centuries and the apparent association with terrestrial climate. Journal of Atmospheric and Terrestrial Physics, (1995). 57(8), 835-845.

LEVITUS S, ANTONOV JI, BOYER TP, STEPHENS C. Warming of the world ocean. Science, (2000). 287 (2225). doi: $10.1126 /$ science.287.5461.2225

LEVITUS S, ANTONOV JI, BOYER TP, BARANOVA OK, GARCIA HE, LOCARNINI RA, ZWENG MM. World ocean heat content and thermosteric sea level change (0-2000 m), 1955-2010. Geophysical Research Letters, (2012). 39(10).

MANTUA NJ, HARE SR, ZHANG Y, WALLACE JM, FRANCIS RC. A Pacific interdecadal climate oscillation with impacts on salmon production. Bulletin of the American Meteorological Society, (1997). 78, pp. 1069-1079.

MEKO D. Dendroclimatic reconstruction with time varying predictor subsets of tree indices. Journal of Climate, (1997). 10(4), 687-696. doi: http://dx.doi.org/10.1175/1520-0442(1997)010<0687:DRWTVP>2.0.CO;2

MOLION LCB. Aquecimento global, El Niños, manchas solares, vulcões e Oscilação Decadal do Pacífico. Climanalise, CPTEC/INPE. (2005).

NEWMAN M, COMPO GP, ALEXANDER MA. ENSO-forced variability of the Pacific decadal oscillation. Journal of Climate, (2003). 16(23), 3853-3857. doi:/10.1175/1520-0442(2003)016<3853: EVOTPD>2.0.CO;2

RAO VB, HADA K. Characteristics of rainfall over Brazil: Annual variations and connections with the Southern Oscillation. Theor Appl Climatol. (1990) 42: 81. doi:10.1007/BF00868215.

RASMUSSON EM, XUELIANG W, ROPELEWSKI CF. The biennial component of ENSO variability. Journal of Marine Systems, (1990). vol. 1, pp. 71-96. doi: 10.1016/0924-7963(90)90153-2. 
TEMPERTON C. Implementation of a Self-Sorting In-Place Prime Factor FFT Algorithm. Journal of Computational Physics, (1985) v. 58, p. 283.

RODGERS KB, FRIEDERICHS P, LAFIT M. Tropical Pacific decadal variability and its relation to decadal modulations of ENSO. Journal of Climate, (2004). 17(19), 3761-3774. doi: http://dx.doi.org/10.1175/1520-0442(2004)017<3761:TPD$\mathrm{VAI}>2.0 . \mathrm{CO} ; 2$

ROPELEWSKI CF, JONES PD. An extension of the Tahiti-Darwin southern oscillation index. Monthly Weather Review, (1987). 115(9), 2161-2165. doi: http://dx.doi.org/10.1175/1520-0493(1987)115<2161:AEOTTS>2.0.CO;2

STAUNING P. Solar activity-climate relations: A different approach. Journal of Atmospheric and Solar-Terrestrial Physics, (2011) Volume 73, Issue 13, August, Pages 1999-2012.doi:10.1016/j.jastp.2011.06.011

WANG G, YAN S, QIAO F. Decadal variability of upper ocean heat content in the Pacific: Responding to the 11-year solar cycle. Journal of Atmospheric and Solar-Terrestrial Physics, (2015), v.135, December, Pages 101-106.

WILLIS JK, ROEMMICH D, CORNUELLE D. Interannual variability in upper ocean heat content, temperature, and thermosteric expansion on global scales, J. Geophys. Res., (2004), 109, C12036, doi:10.1029/2003JC002260.

ZHANG X, CHURCH JA. Sea level trends, interannual and decadal variability in the Pacific Ocean. Geophysical Research Letters, (2012). 39(21). doi: 10.1029/2012GL053240.

ZHANG Y, WALLACE JM, BATTISTI DS. ENSO-like interdecadal variability: 1900-93. J. Climate, (1997). 10, 10041020.

\section{Cleber Souza Corrêa}

Instituto de Aeronáutica e Espaço (IAE), São José dos Campos, São Paulo, Brazil clebercsc@fab.mil.br

Participação do autor:

Concepção do trabalho; aquisição, análise ou interpretação de dados; redigiu o trabalho.

\section{Roberto Lage Guedes}

Instituto de Aeronáutica e Espaço (IAE), São José dos Campos, São Paulo, Brazil roblg331@gmail.com

Participação do autor:

Realizou uma revisão substancial; análise ou interpretação de dados; redigiu o trabalho.

\section{Karlmer Abel Bueno Corrêa}

Instituto Federal Sul Minas Gerais - Campus Machado, Machado, Minas Gerais, Brazil karlmerabc@gmail.com

Participação do autor:

Realizou uma revisão substancial; análise ou interpretação de dados; redigiu o trabalho. 